\title{
The Binding Operation for Mobile IPv6
}

\author{
R.X. Li, D.F. Wang \\ Information Engineering College \\ Zhengzhou University of Science and Technology \\ China
}

\begin{abstract}
Mobile IPv6 is nearly associated with binding update, binding acknowledgement and binding request. With binding update, the mobile nodes get in touch with the home agent or communication fellow. In this paper, the binding operation of IPv6 mobile nodeswas studied; the packet which supports mobile features was analyzed. The results showed that IPv6 has better mobility characteristics.
\end{abstract} request

Keywords-binding update; binding acknowledgement; binding

\section{INTRODUCTION}

The permanent address of host is called home address, which is the address of the host connect to the default network, and the default network is called home network. The obtained address when the mobile node is connected to the external network is called the forwarding address. When the computer was moved from one subnet to another, the IP address should be configured again.

IPv6 is a turning point of mobile computing. In the design of IPv6, the needs to support mobile computing effectively was taken into account [1].The mobility management of IPv6 is the relationship management between home address and forwarding address actually. When a mobile node is connected to an external network, the mobile node delegates its home network router as a representative of itself, and this home network router is called home agent. The home agent usually services for all mobile nodes in home network, it will transmit addressing information to each mobile node. Therefore, home agent need to track all mobile nodes, and records mobile information to the binding memory. The binding memory is the address mapping between home address and forwarding address [2].

\section{OPERATION OF MOBILE NODE}

By the searching function of router in IPv6 the mobile node determines its location [3].Two kinds of packet are defined in the router searching function: router broadcast (option type $=133$ ) and router request (option type=134). The router broadcast packet is sendperiodicallyon the link road by the IPv6 router, and then the mobile node receives the packet periodically. The mobile node can also send router request packet directly, to require the router connected with it to send broadcast packet.

The mobile note checks the prefix of the received broadcast packet, if one of the prefix is match with the home address of the mobile node, then the mobile node will connect to its foreign link, and inform its home agent that it already return to its home link. If there is no prefix match with home address of the mobile node, the mobile node is connected to the foreign link. The mobile node compares the prefix of broadcast packet recently received to the previous received, decide to whether it moves or not. If the mobile node is moved indeed, it will automatically obtain a new forwarding address on the new link by the IPv 6 address configuration function [4], this forward ing address is called primary forwarding address, the forwarding address previously obtained can also be retained, making the mobile node can still receive packets sent to the original address.

\section{A. Getting in Touch with the Home Agent}



FIGURE I. MOBILE NODE GETTING IN TOUCH WITH THE HOME AGENT

Mobile node can send message to its home address regardless of how far it is, so that the home agent can get in touch with the mobile node. When the mobile node is connected to foreign link, the new forwarding address wills be notified to its home agent at first (Figure 1). The mapping between the mobile node and the primary forwarding address is called binding. When the mobile node get a new primary forwarding address, a new binding will be produced, mobile node must send the primary forwarding address to the home agent by binding update message.

\section{B. Getting in Touch with Communication Fellow}

If the mobile node does not connected to its home network, all of the first packet send to it will be received by home agent on halfway, then the home agent will establish a primary tunnel by using the mobile node's primary forwarding address, and the first packet will be forwarded to the mobile node. When the first packet arrives at the mobile node through the tunnel, and the mobile node recognizes this packet is forwarded by the home agent, it will send a binding update message to the communication fellow (Figure 2). When the communication fellow received the bind ing update message, it will create a record in its own binding memory, including home address and forwarding address for the mobile node. This record enables the communication fellow send subsequent packets to forwarding address through routing header directly, rather than using the tunnel (this technology is used only by home agent).

Therefore, among the packet sequences between communication fellows and mobile nodes, only the first packet 
is transmitted through the home agent, the others are sent directly to the mobile node by communication fellows.

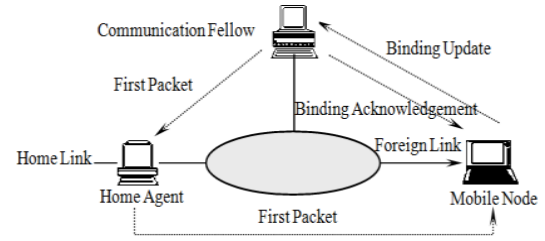

FIGURE II. MOBILE NODE GETTING IN TOUCH WITH COMMUNICATION FELLOW.

\section{Returning to Home Link}

When the mobile node returns to its home link, it checks information of its home network, and sends binding update message to its home agent (figure 3), notify the home agent that it is no longer connected to the foreign link, asking the home agent not to intercepts information which sent to the mobile node. A bit in binding update must be set to 1 and sends a binding update message repeatedly until the home agent issuing binding acknowledgment message.

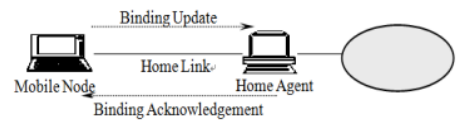

FIGURE III. MOBILE NODE RETURNINGTO HOME LINK.

\section{BINDING OPTION FORMAT}

Three packets which supports mobile features of IPv6 including binding update, binding acknowledgement and binding request, the available options which support mobile features are all put in the extension header. Extension header can be common IPv 6 packets which contain valid user data, or it can be a packet that contains only independent mobile features available options. In the second case, the "next header" field of the options header must be set to the value 59 to indicate that the packet has no other user data [5].

\section{A. Binding Update}

The binding updates are sent by the mobile node it is used to inform the home agents or communication fellows the currently forwarding address of mobile node. When the mobile node get a forwarding address on foreign link, then it will send a binding updates message to the home agent immediately. The $\mathrm{H}$ bit of the binding update is set to 1 , indicate that the mobile node requires the receiving node as its home agent; When the $\mathrm{A}$ bit is set to 1 , indicate that mobile node requires the receiving node to send a binding acknowledgement after it has received the binding update. Binding update option format of IPv6 is shown in Figure 4.

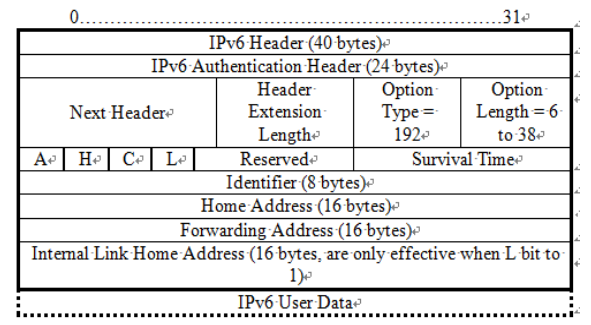

FIGURE IV. BINDING UPDATE OPTIONS.
8 bit "option type" field has the value 192.

8 bit "option length" field is number of bytes of options (not including option type and option length field). In the cases of $\mathrm{C}=0$ and $\mathrm{L}=0$, this field has the minimu $\mathrm{m}$ value of 6 ; In the case of $\mathrm{C}=1$ and $\mathrm{L}=1$, there is a maximu $\mathrm{m} 38$.

$1 \mathrm{~b}$ it a field is set by the source node; it is required to send binding acknowledgement information from the node that receiving the binding update message.

$1 \mathrm{~b}$ it $\mathrm{H}$ field is set by the source node; it is required to take the node that receives the binding update message as its home agent.

1 bit $\mathrm{C}$ field is set by the source node; it indicates the current forwarding address in the binding update.

1 bit L field is set by the source node; it indicates the current internal link home address in the binding update options. It requires to the destination node as the home agent replace mobile node to attend the neighbour discovery process When the place of $\mathrm{L}$ is set, the place of $\mathrm{H}$ must also be set at the same time.

12 bits "reserved" field is reserved for future use. In the process of sending, the filed must be initialized to zero; and in the process of receiving, the field is ignored.

16 bits "survival time" field is survival time in seconds of the binding information. In binding memory, it can be set how long the binding information is valid. Setting a value of 0 indicates that you must delete the binding information from the binding memory, setting a value of 0xFFFF indicates that the binding information must be kept indefinitely.

128 bits "internal link home address" field is the mobile node in a recent connected to the home network using IPv6 link home address. This field is optional settings, only when the field $\mathrm{L}$ is set to 1 , it will work.

\section{B. Binding Acknowledgement}

Binding acknowledgement option is used to confirm the received binding update message. Only when the the A bit of the binding update option is set, made it clear that this option will produce when mobile node send the binding update message. Binding acknowledgement option format is shown in Figure 5 .

8 bits "option type" field has the value 193.

8 bits "option length" field is number of bytes of options (not including option type and option length), the field value is 9.

8 bits "state" field indicates whether the option message has received. If the field value is less than 128, it shows that the binding update message option has been received; otherwise, it shows that the option has been abandoned.

16 bits "refresh" field indicates that it is a period of time, after this period, the mobile node must send binding update message, and then update the information in the binding memory. 


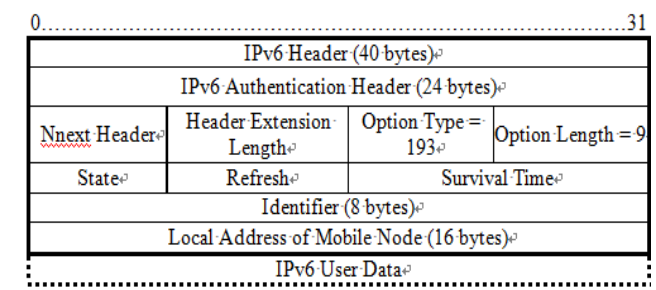

FIGURE V. BINDING ACKNOWLEDGEMENT OPTIONS.

\section{Binding Request}

Binding request option is used to request the mobile node sends a binding update message. Communication fellow send binding request to the mobile node, request the mobile node sends to it a binding update. When the previous binding update information in the survival time is about to expire, and the communication fellow will continue to send data packets to the mobile node, then mobile node can send binding request information. Therefore, the binding acknowledgement is entirely possible to send a message after receiving a binding request. Binding request option format is shown in Figure 6.

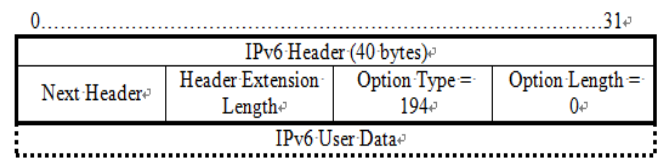

FIGURE VI. BINDING REQUEST OPTIONS.

8 bits "option type" field has the value 194.

8 bits "option length" field is number of bytes of options (not including option type and option length), the field value is 0 .

\section{CONCLUSION}

IPv6 has a huge address space, the mobile nodes can use router broadcast to determine the current link, without foreign agent, the mobile nodes can support mobile feature efficiently. This paper only discusses the binding operation of IPv6, but not involving other field's research such as routing search, address auto configuration, etc.

\section{ACKNOW LEDGEMENT}

This research is supported by the Natural Science Foundation of Henan Province, China (Grant No. 122300410170).

\section{REFERENCES}

[1] Jianhua Li. IPv6 principle and application in mobile communication. Sience Press, 2004.

[2] T.Narten,E.Nordmark,W.Simpson. Neighbor Discovery for IP Version 6 (IPv6).http://www.ietf.org/rfc/rfc1970,1996.

[3] S. Thomson, T. Narten. IPv6 Stateless Address Autoconfiguration .http://www.ietf.or/rfc/rfc1971,1996.

[4] S. Deering, R. Hinden. Internet Protocol, Version 6 (IPv6) Specification. http://www.ietf.or/rfc/rfc1883,1995.

[5] R. Atkinson. IP Authentication Header. http://www.ietf.or/rfc/rfc1826,1995. 